\title{
SETIL: Italian multicentric epidemiological case-control study on risk factors for childhood leukaemia, non hodgkin lymphoma and neuroblastoma: study population and prevalence of risk factors in Italy
}

Corrado Magnani ${ }^{1 *}$, Stefano Mattioli ${ }^{2}$, Lucia Miligi ${ }^{3}$, Alessandra Ranucci ${ }^{4}$, Roberto Rondelli ${ }^{5}$, Alberto Salvan ${ }^{6}$, Luigi Bisanti ${ }^{9}$, Giuseppe Masera ${ }^{7}$, Carmelo Rizzari ${ }^{8}$, Paola Zambon $^{10}$, Santina Cannizzaro ${ }^{11}$, Lorenzo Gafă ${ }^{11}$, Lia Lidia Luzzatto $^{12}$, Alessandra Benvenuti ${ }^{13}$, Paola Michelozzi ${ }^{14}$, Ursula Kirchmayer ${ }^{15}$, Pierluigi Cocco ${ }^{16}$, Pierfranco Biddau ${ }^{17}$, Claudia Galassi ${ }^{18}$, Egidio Celentano ${ }^{19}$, Erni Guarino ${ }^{20}$, Giorgio Assennato ${ }^{21}$, Gigliola de Nichilo ${ }^{22}$, Domenico Franco Merlo ${ }^{23}$, Vittorio Bocchini ${ }^{24}$, Franco Pannelli ${ }^{25}$, Paola Mosciatti ${ }^{26}$, Liliana Minelli ${ }^{27}$, Manuela Chiavarini ${ }^{28}$, Marina Cuttini ${ }^{29}$, Veronica Casotto ${ }^{30}$, Maria Valeria Torregrossa ${ }^{31}$, Rosalia Maria Valenti ${ }^{32}$, Francesco Forastiere ${ }^{33}$, Riccardo Haupt ${ }^{34}$, Susanna Lagorio ${ }^{35}$, Serena Risica ${ }^{36}$ and Alessandro Polichetti ${ }^{36}$

\begin{abstract}
Background: Aetiology of childhood leukaemia and childhood neoplasm is poorly understood. Information on the prevalence of risk factors in the childhood population is limited. SETIL is a population based case-control study on childhood leukaemia, conducted with two companion studies on non-Hodgkin Lymphoma (NHL) and neuroblastoma. The study relies on questionnaire interviews and $50 \mathrm{~Hz}$ magnetic field (ELF-MF) indoor measurements. This paper discusses the SETIL study design and includes descriptive information.

Methods: The study was carried out in 14 Italian regions (78.3\% of Italian population aged 0-10). It included leukaemia, NHL and neuroblastoma cases incident in 0-10 year olds in 1998-2001, registered by the Italian Association of Paediatric Haematology and Oncology (AIEOP) (accrual over 95\% of estimated incidence). Two controls for each leukaemia case were randomly sampled from the Local Health Authorities rolls, matched by gender, birthdate and residence. The same controls were used in NHL and neuroblastoma studies. Parents were interviewed at home on: physical agents (ELF-MF and ionizing radiation), chemicals (smoking, solvents, traffic, insecticides), occupation, medical and personal history of children and parents, infectious diseases, immunizations and associated factors. Occupational exposure was collected using job specific modules. ELF-MF was measured in the main rooms (spot measurement) and close to child's bed (48 hours measurement).
\end{abstract}

Results: The study included: 683 leukaemia cases (87\% ALL, 13\% AnLL), 97 NHL, 155 neuroblastomas, and 1044 controls.

ELF-MF long term measurements were obtained for $61.1 \%$ of controls and $81.6 \%$ of leukaemia cases; $8.8 \%$ of (Continued on next page)

\footnotetext{
* Correspondence: corrado.magnani@cpo.it

'Medical Statistics \& Cancer Epidemiology Unit - Department of Translational Medicine, CPO Piemonte and University of Eastern Piedmont, V. Solaroli 17, Novara 28100, Italy

Full list of author information is available at the end of the article
} 


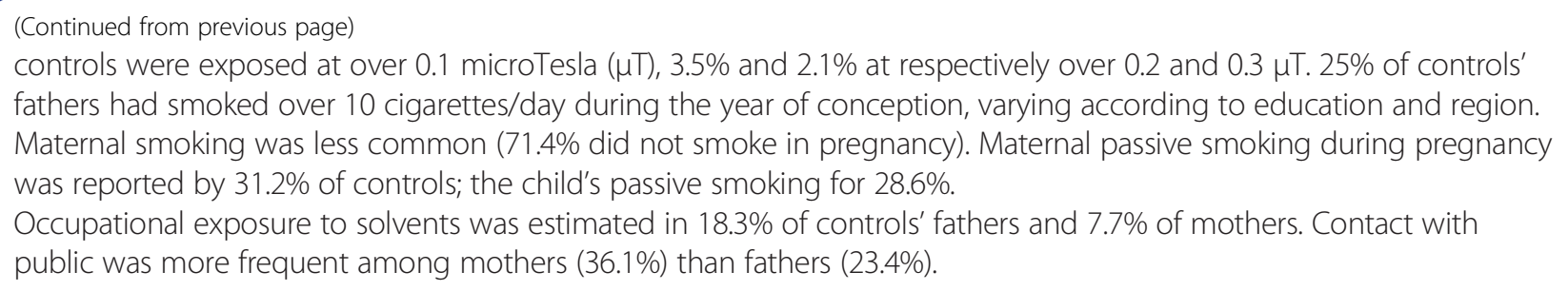

Keywords: Leukaemia, Non hogdkin lymphoma, Neuroblastoma, Epidemiology, Risk factors

\section{Background}

Despite intensive research, the aetiology of childhood neoplasms is still poorly known, even in the case of frequent tumour types such as leukaemia, non-Hodgkin Lymphomas (NHL) [1], and neuroblastoma [2]. Several possible risk factors in the aetiology of childhood leukaemia, have been investigated including ionizing radiations in pregnancy and after birth, Extremely Low-Frequency magnetic fields (ELF-MF) and radiofrequency fields, solvents, pesticides and other chemicals in the environment, infectious agents, immunizations and related factors. With the notable exception of ionizing radiation, research results were not conclusive [1,3-5]. Strong support for an association between exposure to common infections in early childhood (as estimated by day-care attendance) and a reduced risk of acute lymphoblastic leukaemia was provided by a recent meta-analysis of 14 case-control studies [6]. The aetiology of childhood NHL is also poorly known, with the notable exception of Burkitt lymphoma and EBV [3]. Epidemiological studies on neuroblastoma also investigated a wide range of putative risk factors, including: socioeconomic conditions, reproductive history, diagnostic $\mathrm{x}$-rays, maternal exposures in pregnancy, child's characteristics, parental occupation and related exposures, all with inconsistent results; a protective effect was observed from breastfeeding and folates in pregnancy [2].

From a population perspective, the prevalence of exposed children is as important as the estimation of risk since it is the basis for the correct estimation of population attributable fraction and for preventive measures under the framework of the precautionary principle.

A multicentre, population-based case-control epidemiological study (SETIL - Studio Epidemiologico sui Tumori Infantili Linfoemopoietici) was carried out in Italy to investigate risk factors for selected childhood neoplasms. The main study focused on leukaemia and was accompanied by two smaller studies on NHL and neuroblastoma. The study relied on questionnaire based interviews to parents of the study subjects and indoor measurements of $50 \mathrm{~Hz}$ ELF-MF.
Two methodological side studies, including subsets of the main study, were performed on benzene [7] and on gamma radiation exposure [8], in order to obtain information on the occurrence of these exposures and their correlation with ELF-MF.

The present paper illustrates the design of the SETIL study, provides descriptive information on subjects included in the main case-control study, and presents the prevalence of exposure of controls to some of the investigated factors.

\section{Methods}

\section{Cases and controls}

SETIL is a population based case-control study that was carried out in 14 Italian regions (Piedmont, Liguria, Lombardy, The Venetian Region, Friuli Venezia Giulia, Emilia Romagna, Tuscany, Umbria, The Marches, The Latium, Campania, Apulia, Sicily and Sardinia). Cases of leukaemia, non-Hodgkin Lymphoma (NHL) and neuroblastoma in children aged $0-10$ newly diagnosed between August 1998 and December 2001 (with minor regional differences) were eligible for recruitment. The network of paediatric oncology centres affiliated to the Italian Association of Paediatric Haematology and Oncology (AIEOP), i.e. the national network of the Italian childhood cancer centres, was the source of cases. AIEOP runs a nation wide database which records all the new cases of paediatric cancer diagnosed or treated in the network. Cases of paediatric neoplasm are recorded on admission at any AIEOP unit using a common registration form which includes the patient's personal identification data, as well as diagnosis and treatment information. Each new patient is registered using electronic case report forms in the AIEOP "Mod.1.01 Registry" web-based database hosted on the AIEOP website (www.aieop.org) [9]. Estimated coverage of the AIEOP registry in the period of the SETIL study was $94 \%$ for leukaemia, $98 \%$ for neuroblastoma and $100 \%$ for NHL [10]. The list of children eligible for the study was provided monthly by the AIEOP database at each Regional Research Unit by means of authorized access to the 
report area of the database. Only in the Lazio Region a supplementary ad hoc search of eligible cases was carried out through the hospital discharge files of the main Rome paediatric hospital (not in the AIEOP network at the time).

Controls were chosen at random from the population residing in each region, using the Local Health Authority (LHA) rolls. Two controls were randomly sampled for each leukaemia case, matched by gender, date of birth ( \pm 15 days) and LHA of residence. The resulting set of controls was used as a pool in the studies on NHL and neuroblastoma, controlling analyses for age, gender and area of residence. Non participating controls were not substituted.

Date of diagnosis was defined according to the clinical information provided by AIEOP database with cases; for controls a "pseudo diagnosis date" was set equal to the date of diagnosis of the corresponding matched case. Controls retained the assigned pseudo-diagnosis date for the analyses for lymphoma and neuroblastoma substudies. Information was collected until child's diagnosis (or "pseudo diagnosis date" for matched controls). A "reference date" was used to align the time of interest when describing child's typical day and use of (or exposure to) electrical appliances and other exposures. It was defined as one year before diagnosis (if case) or "pseudo diagnosis date" (if controls). For children under 2 at diagnosis, the reference date was corresponding to the age of diagnosis divided by two.

\section{Study presentation to index families}

Regarding the cases, the study was explained to child's parents by the attending oncologist, usually after the induction phase of treatment. Child's parents were contacted by the study staff only after the approval of the attending oncologist. Families of children dying before the study presentation were not excluded from the study but the study presentation was delayed at discretion of the attending clinician until the parents' psychological conditions allowed for it.

Controls' general practitioners (GP) were informed by mail about the child's enrolment in the study and were asked to report their objections, if any. In such instances the study local coordinator contacted the GP in order to decide on the child's inclusion; confirmed GP's refusal was accepted. GPs were welcome to inform the families about the study but this was not required.

\section{Interview}

After medical approval, a research assistant mailed a letter to child's parents with detailed information on the study and, a few days later, called them in order to verify consent and arrange a suitable time for the interview. Interviewers were instructed to carry on several (at least 5) telephone call attempts when needed, at different times and on different days before declaring the subject as non responder. Interviews always took place in the home. Interviewers were not blind about child's status as blinding is practically infeasible in similar studies on childhood neoplasms. They were instructed (see later) in order to avoid any differences when contacting case or control families. A consensus form was signed before the interview.

Although we wished to interview both parents at the same time, we soon realized that this was not always possible. When appropriate, further information regarding the non participating parent was provided by the attending spouse and confirmed or elicited over the phone.

The interviews were conducted according to a standardized questionnaire and were carried out by specifically trained interviewers. The questionnaire was designed for a duration of between 1 hour and 1 hour and 30 minutes.

Items included were:

- Personal and medical history, including reproductive history, pregnancy duration, child conditions at birth, breast feeding, X-rays, childhood diseases and immunizations;

- Exposure to chemical substances at home and in the environment, with focus on solvents, pesticides, traffic pollution, environmental tobacco smoke;

- Checklist on maternal (during pregnancy) and child's home exposure to electrical appliances;

- School attendance, including age at first attendance, school and class size;

- Parental lifelong occupational history, with detailed job and workplace description;

- Parental educational level, measured as the highest level of education attained;

- Child's lifelong and maternal (during pregnancy) residential history, with details on all dwellings, including full addresses, location (urban or rural), indicators of traffic pollution, pesticide environmental exposure and proximity to power lines and broadcasting stations.

Information on parental occupational exposure was collected using different tools: first a lifelong list of occupations (job title and industrial activity) was gathered with corresponding dates of commencement and finish. For each occupation dating from one year before conception until child's diagnosis, further details were collected using job specific modules focused on exposure to solvents, pesticides and other chemicals. Questions on potential ionizing radiation exposure and on EMF sources were also included. Regarding agricultural work, crop-specific modules were prepared, focussing on pesticides and insecticides. The questionnaire is available on request. 


\section{ELF magnetic field measurement}

ELF-MF was measured by the interviewer in the main rooms of the house (usually chosen among the living room, parents' and child's bedroom and kitchen), according to a defined protocol including measurements taken in the centre and corners of each room, with lights and electrical appliances on and off (spot measurements). An ELF-MF meter was left under or close to child's bed for a 48 hours measurement (long-time measurements). Two types of portable meters were used: EMDEX $\mathrm{II}^{\circ}$ for spot measurements and either EMDEXLite $^{\circ}$ or EMDEX $\mathrm{II}^{\circ}$ for long term measurements. Both meters take an instantaneous field measurement on three orthogonal axes at fixed intervals. Sampling interval was set to 4 seconds for spot and to 30 seconds for long term measurements. In the statistical analyses measurements were summarized according to different metrics (arithmetic and geometric means and percentiles). Instantaneous measurements below the detection limit $(0.01 \mu \mathrm{T})$ to compute geometric means were substituted with the value of $0.0001 \mu \mathrm{T}$. All meters were calibrated in laboratory every 6 months and whenever unexpected results were observed. All sets of measurements were inspected graphically using the EMCALC○ software (v.95 and later): defective sets of measurements were excluded and, if possible, repeated. If repetition was not feasible, the measurement was truncated. Evaluation was performed blindly in a laboratory setting by a trained physicist. The protocol for ELF-MF measurement was defined during a pilot study including a random sample of over 100 subjects in 5 regions [11].

The questionnaire included questions on maternal use of mobile and cordless phones during pregnancy and on the distance of dwellings from radio towers or mobile phone stations.

\section{Expert assessment of parental occupational exposure} Occupational exposure to a list of exposures of apriori interest was estimated with expert assessment of the information in the questionnaire and in the job specific modules. Assessment was performed by a team of industrial hygienists and was conducted blindly as to the case or control status. The same procedure was used for both parents.

\section{Interviewer training}

Interviewers were trained during a residential course that took place before the study commencement and was repeated yearly. The first course edition focused on the general principles of the epidemiological study, on the psychological approach to cases' and controls' families, on the questionnaire and on the use of ELF-MF meters. Subsequent editions were more focused on the discussion and the analysis of practical work, based on interviewers' experience.

\section{Power and data analysis}

The power of the study was estimated on the basis of the number of cases expected in the study period (696 ALL, 113 AnLL, 78 NHL and 219 neuroblastoma) [9,10]. Regarding leukaemia, the sample size was large enough to detect moderately increased relative risks as statistically significant (e.g. RR > $=2.8$ with $1 \%$ of exposed and 1.7 with $5 \% ; \alpha=.05,1-\beta=.80)$.

Study management and data registration were carried out using Microsoft Access; statistical analyses using EMCALC $^{\oplus}$ (V.95 and later) (for ELF-MF measurements data), SAS 9.2 and Stata 10.

\section{Ethical committee}

The SETIL study was authorized by the Ethical Review Board for the Piedmont Region (authorization n. 2886, on $15 / 2 / 1999$; letter n. $1852 / 28.3$ on $17 / 2 / 1999$ ) and later by the corresponding board of each participating research unit.

\section{Results}

The study included 14 of the 20 Italians regions, corresponding to $78.3 \%$ of the total Italian population in the $0-10$ age range $(86.9 \%$ in Northern Italy, $100 \%$ in Central Italy and $60.8 \%$ in Southern Italy). In some regions the study was limited to limited areas or was conducted for less than the three year period anticipated according to the protocol Table 1. Lombardy weighed most in the study, followed by the Venetian Region (Veneto). For logistic reasons two research units were active in Sicily, respectively for the Province of Palermo and for the eastern part of the region.

In the study period the eligible cases were as follows: 745 children affected by leukaemia, 116 by NHL and 207 by neuroblastoma. One thousand four hundred seventy five controls were randomly selected and individually matched to leukaemia cases. These numbers excluded the subjects found non eligible during the study process. Participation was $91.7 \%$ for leukaemia, 83.6\% for NHL and $74.9 \%$ for neuroblastoma cases, and $70.8 \%$ for controls. Non participants were not substituted. Family refusal was the most common reason of nonparticipation among controls (70.3\% of non participants) while it was less frequent among non participating cases (leukaemia: 41.9\%, NHL: 31.6\%, neuroblastoma: 40.4\%). Denied medical approval, was obviously more frequent among non-participating cases (leukaemia 45.2\%; NHL $36.9 \%$; neuroblastoma 33.7\%), than among controls (6.3\%). (Table 1). The relative distribution of participant cases and controls by region is presented in the additional material (see Additional file 1: Table S1). All large Italian geographical areas (North, Centre, South and the Islands) were included but the coverage was more comprehensive for the Northern and Central ones. 
Table 1 SETIL study: cases and controls eligible in the study and distribution of non participating subjects by reason of non participation

\begin{tabular}{|c|c|c|c|c|c|c|c|c|}
\hline & \multicolumn{2}{|c|}{ Controls } & \multicolumn{2}{|c|}{ Leukaemia } & \multicolumn{2}{|c|}{ NHL } & \multicolumn{2}{|c|}{ Neuroblastoma } \\
\hline & $\bar{n}$ & $\%$ & $\bar{n}$ & $\%$ & $\bar{n}$ & $\%$ & $\bar{n}$ & $\%$ \\
\hline Total eligible & 1,475 & - & 745 & - & 116 & - & 207 & - \\
\hline Participant & 1,044 & $70.8 \%$ & 683 & $91.7 \%$ & 97 & $83.6 \%$ & 155 & $74.9 \%$ \\
\hline Non participant & 431 & $29.2 \%$ & 63 & $8.3 \%$ & 19 & $16.4 \%$ & 52 & $25.1 \%$ \\
\hline \multicolumn{9}{|l|}{ Reason for non participation } \\
\hline Family refusal & 303 & $70.3 \%$ & 26 & $41.3 \%$ & 6 & $31.6 \%$ & 21 & $40.4 \%$ \\
\hline Medical refusal & 27 & $6.2 \%$ & 7 & $11.1 \%$ & 3 & $15.8 \%$ & 6 & $11.1 \%$ \\
\hline Dying child, medical consensus not obtained & 0 & $0.0 \%$ & 21 & $33.3 \%$ & 4 & $21.1 \%$ & 11 & $21.1 \%$ \\
\hline Adopted, no information on natural family & 4 & $0.9 \%$ & 2 & $3.2 \%$ & 1 & $5.3 \%$ & 0 & $0.0 \%$ \\
\hline Untraced or not approached & 94 & $21.8 \%$ & 6 & $9.5 \%$ & 1 & $5.3 \%$ & 8 & $15.4 \%$ \\
\hline Other and unknown & 3 & $0.7 \%$ & 0 & $0.0 \%$ & 4 & $21.1 \%$ & 6 & $11.5 \%$ \\
\hline
\end{tabular}

Due to the eligible age-range (0-10 years), the great majority of 683 leukaemia cases participant in the study were of the Acute Lymphoblastic Leukaemia (ALL) subtype (594 cases, 87\%), with 7 cases of Acute Hybrid Leukaemia (included in the AnLL group for simplicity), and 82 cases (13\%) of Acute non Lymphoblastic Leukaemia (AnLL). Frequency distribution of AnLL by cytological subtype was: M1: 7.3\%, M1-M2: 14.6\%, M2: 15.9\%, M3: 19.5\%, M4: 12.2\%, M5: 17.1\%, M6: 1.2\%, M7: 2.4, other and unclassified: $9.8 \%$.

Table 2 presents the distribution of participating subjects by selected characteristics. The attained educational level was higher among controls than cases. The level of education among controls was: primary education for $44.3 \%$ of fathers and $38.3 \%$ of mothers; secondary for $40.6 \%$ and $48.2 \%$ and tertiary for $14.5 \%$ and $13.3 \%$. The time lag between diagnosis or pseudo diagnosis and interview was shorter for cases, especially for leukaemia, than for controls: cumulative proportions of interview at 18 months from diagnosis were $75.8 \%$ for leukaemia, $54.9 \%$ for controls, $55.7 \%$ for NHL and $55.5 \%$ for neuroblastoma cases.

Parents' participation was recorded separately for each section of the interview. Overall, mothers attended the interview more often, with participation in the range $98.2 \%$ of interviews (section on dwellings) to $99.0 \%$ (maternal occupation), while fathers' participation was in the range $62.5 \%$ (section on dwellings) to $69.5 \%$ (section on general information). Additional information on occupation was provided at a later time by $4 \%$ of fathers. No differences were observed for maternal participation by case/control status while limited differences were observed for paternal participation, that was lower for controls and also for lymphoma cases (Additional file 1: Table S2).

The participation to ELF-MF long term measurements is summarized in the supplementary material (Additional file 1: Tables S3). The overall proportion of eligible subjects with measurement is lower for controls (61\%) and highest for the leukaemia cases (82\%), depending on the participation in the interview: among those who accepted it, the proportion without measurements is similar in the cases and controls.

Prevalence of infectious diseases until reference time are summarized in Table 3. Chickenpox was reported for $35.0 \%$ of controls, followed by mumps (11.4\%). For all diseases included in the checklist, in most instances the diagnosis was reported as "confirmed by a medical doctor". High temperature and illness affecting the upper airways (colds, throat infections, sinusitis, ear infections...) in the first year of life were reported by $62.5 \%$ of controls, with medical confirmation in $93.1 \%$. More serious diseases of likely infectious origin, such as bronchitis (16\%) or pneumonia $(0.8 \%)$ were much rarer.

Parental smoking habits were considered focussing on the year of conception for the father and on the pregnancy for the mother (Table 4): two different indicators were used to summarize questionnaire information: for fathers cigarettes/day during the year of conception and for mothers the cumulative number of packs summed over the pregnancy. Over a quarter of controls' fathers reported smoking over 10 cigarettes/day during the year of conception: the proportion varied according to education (a higher smoking prevalence was observed among the less educated) and region (North to South increasing gradient). Maternal smoking was less common $(71.4 \%$ non smokers, $25 \%$ in the category up to 100 packs and $3.2 \%$ in the category over 100 packs as cumulative consumption during pregnancy) and their level of education appeared to have a smaller impact (higher smoking prevalence among the less educated) and region (higher smoking prevalence in Central Italy regions). 
Table 2 SETIL study: frequency distribution of participating subjects by condition, gender, child's age, year of diagnosis, lag between diagnosis and interview (months), parental education level, maternal age at child's birth

\begin{tabular}{|c|c|c|c|c|c|c|c|c|c|}
\hline & & \multicolumn{2}{|l|}{ Controls } & \multicolumn{2}{|c|}{ Leukaemia } & \multicolumn{2}{|l|}{$\mathrm{NHL}$} & \multicolumn{2}{|c|}{ Neuroblastoma } \\
\hline & & $n$ & $\%$ & $n$ & $\%$ & $n$ & $\%$ & $n$ & $\%$ \\
\hline \multirow[t]{3}{*}{ Gender } & Girls & 482 & 46.2 & 313 & 45.8 & 19 & 19.6 & 63 & 40.6 \\
\hline & Boys & 562 & 53.8 & 370 & 54.2 & 78 & 80.4 & 92 & 59.4 \\
\hline & Total & 1044 & 100.0 & 683 & 100.0 & 97 & 100.0 & 155 & 100.0 \\
\hline \multirow[t]{4}{*}{ Age } & {$[0 ; 2)$} & 156 & 14.9 & 95 & 13.9 & 5 & 5.2 & 88 & 56.8 \\
\hline & {$[2 ; 4)$} & 351 & 33.6 & 243 & 35.6 & 10 & 10.3 & 33 & 21.3 \\
\hline & {$[4 ; 6)$} & 233 & 22.3 & 146 & 21.4 & 14 & 14.4 & 25 & 16.1 \\
\hline & {$[6 ; 11)$} & 304 & 29.1 & 199 & 29.1 & 68 & 70.1 & 9 & 5.8 \\
\hline \multirow[t]{4}{*}{ Year of diagnosis } & 1998 & 109 & 10.4 & 67 & 9.8 & 7 & 7.2 & 20 & 12.9 \\
\hline & 1999 & 314 & 30.1 & 212 & 31.0 & 32 & 33.0 & 35 & 22.6 \\
\hline & 2000 & 342 & 32.8 & 229 & 33.5 & 32 & 33.0 & 57 & 36.8 \\
\hline & 2001 & 279 & 26.7 & 175 & 25.6 & 26 & 26.8 & 43 & 27.7 \\
\hline \multirow[t]{4}{*}{ Lag diagnosis - interview (months) } & {$[0 ; 6)$} & 30 & 2.9 & 29 & 4.2 & 5 & 5.2 & 5 & 3.2 \\
\hline & {$[6 ; 12)$} & 170 & 16.3 & 192 & 28.1 & 21 & 21.6 & 30 & 19.4 \\
\hline & {$[12 ; 18)$} & 373 & 35.7 & 297 & 43.5 & 28 & 28.9 & 51 & 32.9 \\
\hline & [18 and over] & 471 & 45.1 & 165 & 24.2 & 43 & 44.3 & 69 & 44.5 \\
\hline \multirow[t]{4}{*}{ Maternal education } & Primary & 400 & 38.3 & 320 & 46.9 & 43 & 44.3 & 66 & 42.6 \\
\hline & High school & 503 & 48.2 & 285 & 41.7 & 44 & 45.4 & 75 & 48.4 \\
\hline & University d. & 139 & 13.3 & 78 & 11.4 & 10 & 10.3 & 14 & 9.0 \\
\hline & Missing data & 0 & 0.0 & 0 & 0.0 & 0 & 0.0 & 0 & 0.0 \\
\hline \multirow[t]{4}{*}{ Paternal education } & Primary & 463 & 44.3 & 340 & 49.8 & 47 & 48.5 & 81 & 52.3 \\
\hline & High school & 424 & 40.6 & 268 & 39.2 & 39 & 40.2 & 57 & 36.8 \\
\hline & University d. & 151 & 14.5 & 70 & 10.2 & 11 & 11.3 & 16 & 10.3 \\
\hline & Missing data & 6 & 0.6 & 5 & 0.7 & 0 & 0.0 & 1 & 0.6 \\
\hline Maternal age at child's birth & Mean (SD) & 29.66 & $(4.76)$ & 29.84 & $(4.91)$ & 29.84 & $(4.86)$ & 30.10 & $(4.75)$ \\
\hline Paternal age at child's birth & Mean (SD) & 33.95 & $(5.40)$ & 33.13 & $(5.61)$ & 32.66 & $(5.27)$ & 33.79 & $(5.52)$ \\
\hline
\end{tabular}

Passive smoking for pregnant mothers was reported by $31.2 \%$ of controls, with $9.4 \%$ in the highest category of 4 hours of exposure per day (Table 5). Child's passive smoking was summarized in a cumulative index counting a number of cigarettes up to the reference date, considering all sources (most notably parents and relatives). Exposure to passive smoking was reported for $28.6 \%$ of controls, with $11.4 \%$ in the highest category of over 7000 cigarettes (Table 5). For both maternal and child's passive smoking the trends were as for active parental smoking: higher exposure among the less educated and North to South increasing gradient.

Table 6 presents exposure ELF-MF, according to the results of long term ELF-MF measurements. Results were summarized according to the following metrics: arithmetic and geometric mean, median and $90^{\circ}$ and $95^{\circ}$ percentile, grouped in four classes $(<0.1,0.1-0.2,0.2-0.3$ and over $0.3 \mu \mathrm{T})$. Data from the arithmetic mean showed $8.8 \%$ of controls were exposed at over $0.1 \mu \mathrm{T}$, $3.5 \%$ at over $0.2 \mu \mathrm{T}$ and $2.1 \%$ at over $0.3 \mu \mathrm{T}$.
The distribution of controls' parents according to job description and condition from one year before conception to the child's diagnosis is presented in the supplementary material (Additional file 1: Table S4 and S5, respectively). Almost all fathers of control children were employed at the study time: only $1.3 \%$ described themselves as "never employed". On the contrary $13.3 \%$ of mothers reported themselves as "never employed", with large regional variations.

Occupational exposure to solvents (at any time from one year before conception until child's diagnosis) was observed for $18.3 \%$ of controls' fathers and $7.7 \%$ of controls' mothers (Table 7). Corresponding proportions of exposed to benzene were $3.3 \%$ and $0.3 \%$. Contact with public was more frequent among mothers (36.1\%) than fathers (23.4\%).

\section{Discussion}

This paper presents methods and summarizes descriptive results of the SETIL Italian case-control study on 
Table 3 SETIL study: prevalence of common infections among controls

\begin{tabular}{|c|c|c|c|c|c|c|c|}
\hline & & \multicolumn{2}{|l|}{ Yes } & \multicolumn{2}{|c|}{ Missing } & \multicolumn{2}{|c|}{ MD confirmation } \\
\hline & & $\bar{N}$ & $\%$ & $\bar{N}$ & $\%$ & $\bar{N}$ & $\%$ \\
\hline \multirow[t]{9}{*}{ At any time before reference date } & Measles & 62 & 5.9 & 5 & 0.5 & 61 & 98.4 \\
\hline & Pertussis & 67 & 6.4 & 4 & 0.4 & 65 & 97.0 \\
\hline & Rubella & 49 & 4.7 & 6 & 0.6 & 44 & 89.8 \\
\hline & Chicken pox & 365 & 35.0 & 1 & 0.1 & 355 & 97.3 \\
\hline & Mumps & 119 & 11.4 & 5 & 0.5 & 113 & 95.0 \\
\hline & Scarlet fever & 80 & 7.7 & 6 & 0.6 & 78 & 97.5 \\
\hline & Mononucleosis & 12 & 1.2 & 3 & 0.3 & 11 & 91.7 \\
\hline & Herpes Labialis & 25 & 2.4 & 1 & 0.1 & 15 & 60.0 \\
\hline & Herpes Oral mucosae & 44 & 4.2 & 2 & 0.2 & 38 & 86.4 \\
\hline \multirow[t]{5}{*}{ First year of life. } & Febrile diseases - respiratory tract & 653 & 62.6 & 9 & 0.9 & 608 & 93.1 \\
\hline & Bronchitis & 167 & 16.0 & 5 & 0.5 & 165 & 98.8 \\
\hline & Pneumonia & 8 & 0.8 & 6 & 0.6 & 8 & 100.0 \\
\hline & G.U. infections & 43 & 4.1 & 6 & 0.6 & 42 & 97.7 \\
\hline & Febrile diseases - unspecified & 46 & 4.4 & 9 & 0.9 & 36 & 78.3 \\
\hline
\end{tabular}

Percentages are computed over the number of participant controls.

childhood leukaemia, NHL and neuroblastoma. It also provides a first description of the extent of exposure of Italian children in pre-school and primary school age to some putative risk factors for leukaemia.

Distribution of cases by age and gender was very close to expectations according to the population cancer registry data [12].
Participation in the study was almost complete for leukaemia cases and over $80 \%$ for lymphoma and neuroblastoma cases. The difference is likely to depend on the longer time requested for the therapy and the larger proportion of children that were not in remission. Attending clinicians recommended not to contact cases' families until the conclusion of the induction phase of the therapy.

Table 4 SETIL study parental smoking status of controls classified according to child's residence, and parental educational level

\begin{tabular}{|c|c|c|c|c|c|c|c|c|c|c|c|c|c|c|c|c|}
\hline & & \multicolumn{7}{|c|}{ Paternal smoking } & \multicolumn{7}{|c|}{ Maternal smoking } & \multirow{3}{*}{$\begin{array}{l}\text { Tota } \\
\mathrm{N} \\
\end{array}$} \\
\hline & & \multicolumn{2}{|c|}{ Nonsmoker $^{a}$} & \multicolumn{2}{|c|}{$\begin{array}{l}\text { Moderate } \\
\text { smoker }^{\mathrm{b}}\end{array}$} & \multicolumn{2}{|c|}{$\begin{array}{l}\text { Heavy } \\
\text { smoker }^{c}\end{array}$} & \multirow{2}{*}{$\begin{array}{l}\text { Missing } \\
\mathrm{N}\end{array}$} & \multicolumn{2}{|c|}{ Nonsmoker } & \multicolumn{2}{|c|}{$\begin{array}{l}\text { Moderate } \\
\text { smoker }^{\mathrm{e}}\end{array}$} & \multicolumn{2}{|c|}{$\begin{array}{l}\text { Heavy } \\
\text { smoker }^{\mathrm{f}}\end{array}$} & \multirow{2}{*}{$\begin{array}{l}\text { Missing } \\
\mathrm{N}\end{array}$} & \\
\hline & & $\mathbf{N}$ & $\%$ & $\mathrm{~N}$ & $\%$ & $\mathrm{~N}$ & $\%$ & & $\mathrm{~N}$ & $\%$ & $\mathrm{~N}$ & $\%$ & $\mathrm{~N}$ & $\%$ & & \\
\hline \multicolumn{2}{|l|}{ Total } & 571 & 55.3 & 188 & 18.2 & 273 & 26.5 & 12 & 745 & 71.4 & 265 & 25.4 & 33 & 3.2 & 1 & 1044 \\
\hline \multirow[t]{4}{*}{ Education } & Less than high school & 211 & 45.8 & 80 & 17.3 & 170 & 36.9 & 2 & 275 & 67.9 & 115 & 28.4 & 15 & 3.7 & 0 & 405 \\
\hline & High school & 253 & 60.2 & 80 & 19.1 & 87 & 20.7 & 4 & 372 & 74.4 & 114 & 22.8 & 14 & 2.8 & 1 & 501 \\
\hline & University & 107 & 71.3 & 27 & 18.0 & 16 & 10.7 & 1 & 96 & 70.6 & 36 & 26.5 & 4 & 2.9 & 0 & 136 \\
\hline & Missing & 0 & & 1 & & 0 & & 5 & 2 & & 0 & & 0 & & 0 & 2 \\
\hline \multirow[t]{4}{*}{ Residence } & North. Italy (excl. Lombardy) & 155 & 62.5 & 40 & 16.1 & 53 & 21.4 & 2 & 186 & 74.4 & 56 & 22.4 & 8 & 3.2 & & 250 \\
\hline & Lombardy & 146 & 57.3 & 50 & 19.6 & 59 & 23.1 & 5 & 190 & 73.4 & 60 & 23.2 & 9 & 3.5 & 1 & 260 \\
\hline & Central Italy & 140 & 55.3 & 47 & 18.6 & 66 & 26.1 & 4 & 171 & 66.5 & 82 & 31.9 & 4 & 1.6 & & 257 \\
\hline & Southern Italy & 130 & 47.1 & 51 & 18.5 & 95 & 34.4 & 1 & 198 & 71.5 & 67 & 24.2 & 12 & 4.3 & & 277 \\
\hline
\end{tabular}

Paternal smoking is referred at child conception and maternal smoking during pregnancy.

Percentages are calculated by row, on subjects with available information.

${ }^{a}$ Nonsmoker category includes never smokers and fathers who quitted smoking at least the year before conception.

${ }^{b}$ Moderate smoker category includes fathers who quitted smoking in the year of the conception and smokers of 1-10 cigarettes per day in the period of

the conception.

${ }^{\mathrm{c}}$ Heavy smoker category includes fathers that smoked 11 or more cigarettes per day in the period of the conception.

${ }^{d}$ Nonsmoker category includes never smokers and mothers who quitted smoking at least the year before the pregnancy.

${ }^{\mathrm{e}}$ Moderate smoker category includes mothers who quitted smoking in the year of the pregnancy and women that smoked 1-100 packets of cigarettes during the pregnancy.

${ }^{f}$ Heavy smoker category includes mothers that smoked 101 or more packets of cigarettes during the pregnancy. 
Table 5 SETIL study prevalence of exposure to passive smoking among controls: maternal exposure during pregnancy and child's exposure to environmental tobacco smoke, by child's age, residence, and parental educational level

\begin{tabular}{|c|c|c|c|c|c|c|c|c|c|c|c|}
\hline & & \multicolumn{9}{|c|}{ Maternal exposure to environmental tobacco smoke during pregnancy } & \multirow{3}{*}{$\begin{array}{l}\text { TOTAL } \\
\mathbf{N}\end{array}$} \\
\hline & & \multicolumn{2}{|c|}{ Not exposed ${ }^{a}$} & \multicolumn{2}{|c|}{$<2.00$ hours/day ${ }^{\mathrm{a}}$} & \multicolumn{2}{|c|}{ 2.00-3.99 hours/day ${ }^{\mathrm{a}}$} & \multicolumn{2}{|c|}{$\geq 4.00{\text { hours } / \text { day }^{\mathrm{a}}}$} & \multirow{2}{*}{$\begin{array}{l}\text { Missing } \\
\mathrm{N}\end{array}$} & \\
\hline & & $\mathrm{N}$ & $\%$ & $\mathrm{~N}$ & $\%$ & $\mathrm{~N}$ & $\%$ & $\mathrm{~N}$ & $\%$ & & \\
\hline Total & & 710 & 68.8 & 122 & 11.8 & 103 & 10.0 & 97 & 9.4 & 12 & 1044 \\
\hline \multirow[t]{4}{*}{ Education (Mother) } & Less than high school & 249 & 62.4 & 48 & 12.0 & 55 & 13.8 & 47 & 11.8 & 6 & 405 \\
\hline & High school & 349 & 70.4 & 66 & 13.3 & 35 & 7.1 & 46 & 9.3 & 5 & 501 \\
\hline & University & 110 & 81.5 & 8 & 5.9 & 13 & 9.6 & 4 & 3.0 & 1 & 136 \\
\hline & Missing & 2 & & 0 & & 0 & & 0 & & 0 & 2 \\
\hline \multirow[t]{7}{*}{ Residence } & Northern Italy (excl. Lombardy) & 180 & 72.6 & 28 & 11.3 & 18 & 7.3 & 22 & 8.9 & 2 & 250 \\
\hline & Lombardy & 199 & 77.1 & 20 & 7.8 & 18 & 7.0 & 21 & 8.1 & 2 & 260 \\
\hline & Central Italy & 179 & 70.7 & 22 & 8.7 & 26 & 10.3 & 26 & 10.3 & 4 & 257 \\
\hline & Southern Italy & 152 & 55.7 & 52 & 19.0 & 41 & 15.0 & 28 & 10.3 & 4 & 277 \\
\hline & & \multicolumn{9}{|c|}{ Exposure of children to environmental tobacco smoke (as total number of cigarettes) } & \\
\hline & & \multicolumn{2}{|c|}{ Not exposed ${ }^{a}$} & \multicolumn{2}{|c|}{$<1000$ cigarettes $^{\mathrm{a}}$} & \multicolumn{2}{|c|}{ 1000-6999 cigarettes $^{\mathrm{a}}$} & \multicolumn{2}{|c|}{$\geq 7000$ cigarettes $^{a}$} & Missing & Total \\
\hline & & $\mathbf{N}$ & $\%$ & $\mathbf{N}$ & $\%$ & $\mathbf{N}$ & $\%$ & $\mathrm{~N}$ & $\%$ & $\mathrm{~N}$ & $\mathbf{N}$ \\
\hline Total & & 740 & 71.4 & 91 & 8.8 & 88 & 8.5 & 118 & 11.4 & 7 & 1044 \\
\hline \multirow[t]{4}{*}{ Age } & {$[0-2)$} & 119 & 76.8 & 19 & 12.3 & 15 & 9.7 & 2 & 1.3 & 1 & 156 \\
\hline & {$[2-4)$} & 255 & 73.1 & 41 & 11.7 & 25 & 7.2 & 28 & 8.0 & 2 & 351 \\
\hline & {$[4-6)$} & 161 & 69.1 & 24 & 10.3 & 13 & 5.6 & 35 & 15.0 & 0 & 233 \\
\hline & {$[6-11)$} & 205 & 68.3 & 7 & 2.3 & 35 & 11.7 & 53 & 17.7 & 4 & 304 \\
\hline \multirow[t]{4}{*}{ Education (Both parents) } & Both parents less than high school degree & 283 & 61.1 & 52 & 11.2 & 51 & 11.0 & 77 & 16.6 & 3 & 466 \\
\hline & At least one high school degree & 337 & 79.5 & 29 & 6.8 & 25 & 5.9 & 33 & 7.8 & 3 & 427 \\
\hline & At least one university degree & 120 & 80.0 & 10 & 6.7 & 12 & 8.0 & 8 & 5.3 & 1 & 151 \\
\hline & Missing & 0 & & 0 & & 0 & & 0 & & & \\
\hline \multirow[t]{4}{*}{ Residence } & Northern Italy (excl. Lombardy) & 186 & 75.0 & 20 & 8.1 & 18 & 7.3 & 24 & 9.7 & 2 & 250 \\
\hline & Lombardy & 211 & 81.1 & 22 & 8.5 & 11 & 4.2 & 16 & 6.1 & 0 & 260 \\
\hline & Central Italy & 197 & 77.6 & 10 & 3.9 & 21 & 8.3 & 26 & 10.2 & 3 & 257 \\
\hline & Southern Italy & 146 & 53.1 & 39 & 14.2 & 38 & 13.8 & 52 & 18.9 & 2 & 277 \\
\hline
\end{tabular}

Percentages are calculated by row. Information on maternal exposure missing for 15 controls.

a: Categories of exposure to Environmental Tobacco smoke are based on tertiles of exposure among exposed controls, rounded to the nearest half hour (maternal exposure) or to the nearest thousand (child's exposure). 
Table 6 SETIL study prevalence of exposure to ELF-MF among controls (Total n.: 904 with ELF-MF measurements)

\begin{tabular}{|c|c|c|c|c|c|c|c|c|}
\hline \multirow[b]{3}{*}{ Metric } & \multicolumn{8}{|c|}{ Results of ELF-MF measurements $(\mu \mathrm{T})$} \\
\hline & \multicolumn{2}{|c|}{$<=0.1$} & \multicolumn{2}{|c|}{$(0.1-0.2]$} & \multicolumn{2}{|c|}{$(0.2-0.3]$} & \multicolumn{2}{|c|}{$>0.3$} \\
\hline & $\mathbf{N}$ & $\%$ & $\mathbf{N}$ & $\%$ & $\mathbf{N}$ & $\%$ & $\mathbf{N}$ & $\%$ \\
\hline Arithmetic mean & 824 & 91.15 & 48 & 5.31 & 13 & 1.44 & 19 & 2.10 \\
\hline Geometric mean & 837 & 92.58 & 43 & 4.76 & 11 & 1.22 & 13 & 1.44 \\
\hline Median & 842 & 93.14 & 36 & 3.98 & 11 & 1.22 & 15 & 1.66 \\
\hline $90^{\circ}$ percentile & 754 & 83.41 & 91 & 10.07 & 19 & 2.10 & 40 & 4.42 \\
\hline $95^{\circ}$ percentile & 721 & 79.76 & 112 & 12.39 & 27 & 2.99 & 44 & 4.86 \\
\hline $99^{\circ}$ percentile & 659 & 72.90 & 126 & 13.94 & 53 & 5.86 & 66 & 7.30 \\
\hline
\end{tabular}

In our study controls were sampled from the LHA rosters and therefore participation rate could be accurately measured. Case names were selected in the same data base used for sampling controls, to check the correspondence between case and control sources, and were always found. Participation of controls' families reached $70.8 \%$, a figure that is similar or higher than the results observed in other studies on the topic with population based recruitment. Linet et al. [13] obtained an interview from $72.8 \%$ of controls and a ELF-MF measurement from 63\%. In the UK study [14] participation of controls was $64 \%$, while it was $62.0 \%$ in the German study by Schuz et al. [15].

Table 7 SETIL study prevalence of occupational exposure of among control's parents

\begin{tabular}{|c|c|c|c|c|}
\hline \multirow[t]{2}{*}{ EXPOSURE } & \multicolumn{2}{|c|}{ FATHER } & \multicolumn{2}{|c|}{ MOTHER } \\
\hline & $\mathbf{N}$ & $\%$ & $\mathbf{N}$ & $\%$ \\
\hline Any solvent & 189 & 18.3 & 80 & 7.7 \\
\hline - Aromatic hydrocarbons & 98 & 9.5 & 18 & 1.7 \\
\hline - Chlorinated hydrocarbons & 61 & 5.6 & 33 & 3.2 \\
\hline - Technical hydrocarbons & 92 & 8.9 & 17 & 1.6 \\
\hline - Aliphatic hydrocarbons & 69 & 6.7 & 13 & 1.2 \\
\hline - Derivate oxygenate hydrocarbons & 75 & 7.2 & 45 & 4.3 \\
\hline Benzene & 34 & 3.3 & 3 & 0.3 \\
\hline Chloroform & 2 & 0.2 & 0 & 0 \\
\hline Dichloromethane & 14 & 1.3 & 15 & 1.4 \\
\hline Dioxane & 1 & 0.1 & 0 & 0 \\
\hline Styrene & 9 & 0.9 & 3 & 0.3 \\
\hline Tetracloroethane & 25 & 2.4 & 5 & 0.5 \\
\hline Trichloroethylene & 27 & 2.6 & 8 & 0.8 \\
\hline 1,1,1 trichloroethane & 15 & 1.4 & 1 & 0.1 \\
\hline Toluene & 73 & 7.0 & 12 & 1.1 \\
\hline Xylene & 69 & 6.6 & 10 & 1.0 \\
\hline Acetamide & 0 & 0 & 0 & 0 \\
\hline Acrylonitrile & 7 & 0.7 & 0 & 0 \\
\hline P. aminoazobenzene & 0 & 0 & 1 & 0.1 \\
\hline
\end{tabular}

Percentages are computed over the number of participant controls.
Ma et al. observed in California that control participation was $78.2 \%$ of those who accepted a first contact with the study [16], corresponding to an estimated fraction of $49 \%$ of those eligible.

Participant control parents' education was comparable to figures provided by the Italian National Institute of Statistics (ISTAT) for the general population of a corresponding age. In the 2001 census, the proportion of subjects with high school diploma or university degree in age class $19-34$ was $50.1 \%$ for men and $57.9 \%$ for women [17]. With reference to 2004-2005 period figures were also available for University and High school degree, separately. The proportion of men with University degrees or Tertiary Education was: $2.8 \%$ in the $20-24$ age group, $11.6 \%$ in the $25-25$ age group, $13.5 \%$, in the $30-34$ age group, and $12.2 \%$, in the $35-39$ age group. Corresponding proportions with high school diploma were: $67.5 \%$ in the $20-24$ age group, $43.8 \%$ in the $25-29$ age group, $37.8 \%$ in the $30-34$ age group and $34.0 \%$ in the 35-39 age group. In women the proportion with a University Degree was: age 20-24: 3.9\%, age 25-29: $14.2 \%$, age $30-34: 17.2 \%$, age $35-39$ : $12.3 \%$; corresponding proportions with high school diploma were: age 20-24: 69.0\%, age $25-29: 50.9 \%$, age $30-34: 40.5 \%$, age $35-39$ : $34.1 \%$. [18].

The database of ELF-MF measurements included 904 controls, corresponding to an overall participation of $61.1 \%$. Almost $90 \%$ of the interviewed subjects also participated in the ELF-MF measurements. To our knowledge, this is the largest Italian database on long term measurements of ELF-MF exposure in the general population and will be valuable for additional analyses on ELF-MF exposure by region and by other covariates, such as socioeconomic variables. The proportion of controls with estimated exposure to ELF-MF over $0.3 \mu \mathrm{T}$ was $1.44 \%$ (Geometric mean; 95\% CI $0.84 \%-2.45 \%$ ) in the present study, higher than, but not incompatible with the proportion of controls living in dwellings with long term measured ELF magnetic fields above $0.3 \mu \mathrm{T}$ observed in the European studies included in the pooled analyses by Greenland et al. [19], Ahlbom et al. [20], and Kheifets et al. [21]. The difference is sensitive to the metric used to summarize the individual measures, therefore we decided to present results according to different metrics: in the studies included in the Greenland et al. [19] pooled analysis, the proportion of controls living in dwellings with ELF-MF higher than $0.3 \mu \mathrm{T}$ (summarized using the arithmetic mean) was estimated in $1.33 \%$, while in the present study the corresponding proportion was $2.10 \%$ (95\% CI: $1.35 \%-3.26 \%$ ). If all studies with measured fields in those pooled analyses are considered, the proportion of controls exposed to over $0.3 \mu \mathrm{T}$ increased to $1.9 \%$ (our computation from tabulated data), because of the larger proportions of controls in 
the right tail of the exposure distribution recorded in non-European studies.

In our study we focused on paternal smoking at the conception and on maternal smoking during pregnancy: $55.3 \%$ of controls fathers and $71.4 \%$ of mothers stated at the interview they were non smokers while $44.7 \%$ and $28.5 \%$ described themselves as smokers. These figures are close to reports from Italian surveys on corresponding periods. Sardu et al. [22] estimated the proportion of smokers by age group, gender and period, based on a national survey from ISTAT: in 1995 (centre of the yearof-birth distribution in our study) prevalence of smokers in men was $43 \%$ in age $20-24,47 \%$ in age $25-29$ and $45 \%$ in age to $30-35$. Corresponding figures in women were $24 \%, 30 \%$ and $32 \%$, close to our results. A trend was observed in education levels, more marked in men but also present in women. In the 2000 survey on smoking habits in Italy, Federico et al. [23] observed that in the 25-49 age group smoking prevalence was higher in the lower education group, both in men (OR of smoking in lower vs higher education: 1.71) and in women (OR: 1.12). In our study heavy smokers (defined as regular smokers of 11 or more cigarettes/day) were $26.5 \%$ of fathers and $3.2 \%$ of mothers: these figures were lower than those measured in a survey on smoking in Italian men and women in 2001, that reported an average 18.8 cigarettes per day in men and 12.2 in women [24]. However the difference may depend on a protective attitude of parents, who in spite of not stopping are likely to reduce the amount smoked, as was observed in studies on mortality by marital status and parenthood $[25,26]$. The same study also observed a lower prevalence in the North of Italy [24], corresponding to our results.

Compared to results on smoking exposure reported in recent international studies, our results shows similar prevalence of smokers among fathers and lower prevalence among mothers. The study carried out in France by Rudant et al. [27] investigated a European population with smoking habits not very different from Italian population: $5.6 \%$ of control mothers reported 10 or more cigarettes/day during pregnancy. The period considered for fathers (from birth to interview) is different from the one considered in our study, nevertheless it is of interest that $34.0 \%$ of fathers reported 10 or more cigarettes/day. In the study carried out in Canada by MacArthur et al. [28] prevalence of smoking (10 or more cigarettes per day) in pregnancy among controls was $21.6 \%$ for mothers, while and $40.6 \%$ of fathers of controls reported smoking before index child pregnancy. Lee et al. [29] in Korea reported that $80.4 \%$ of (hospital) controls' fathers smoked in the year of child's pregnancy. In Milne et al. [30] study, $12.3 \%$ of mothers of controls reported having smoked 15 or more cigarettes /day during pregnancy and $19.6 \%$ of fathers reported having smoked 15 or more cigarettes /day in the year of conception. The association of parental smoking and leukemia in the SETIL study was addressed by Mattioli et al. [31] for AnLL and by Farioli et al. [32] for ALL.

The SETIL study investigated occupational exposure to chemical substances and other agents using the expert assessment procedure. Results on solvents exposure were presented elsewhere [33]. Although such a procedure has been frequently used in occupational studies on adult cancer since the 80's [34], its application in the investigation on parental exposure and childhood cancer has been limited so far. The different methodology in evaluating parental exposure and the different information provided in reports are serious limits in comparing the prevalence of exposure of controls across different studies and therefore only limited comparisons can be carried on. Solvent exposure was evaluated in different studies but only a few provided information useful for estimating parental prevalence of exposure: Bukley et al. [35] using self reported information evaluated that $61 / 178$ controls had paternal solvent exposure and that in $23.6 \%(42 / 178)$ such exposure had lasted over 1000 days. Schuz et al. [36] estimated the prevalence of paternal and maternal exposure to solvents at any time before interview in $12.9 \%(382 / 2962)$ controls and in 5.0 (147/ 2962) of controls, respectively. Reid et al. [37] estimated the prevalence of paternal and maternal exposure to solvents at any time before child birth in 51\% (382/748) controls and in $13 \%(114 / 854)$ of controls, respectively. Corresponding prevalence one year before birth was $25 \%$ $(189 / 748)$ and $4 \%(31 / 854)$, respectively. In our study and considering controls, experts assigned exposure to solvents to $18.3 \%$ of fathers and $7 \%$ of mothers.

\section{Conclusions}

Our results showed that the exposure of Italian children to cancer risk factors is not negligible, consistently with other countries of Western life style and industrial economy. Even if the association of common risk factors such as smoking with childhood leukemia is debated, they clearly represent risk factors for other diseases in childhood, such as asthma and acute respiratory illnesses. SETIL study results on prevalence of exposure indicate the need to take a stronger stance to reduce it, as it directly concern a large proportion of parents and indirectly affect their children.

Large size population based case control studies are a major resource for providing information on prevalence of exposure, as shown in this report. The Italian case-control study on childhood leukaemia, NHL and neuroblastoma (SETIL study) represents a useful source of data to estimate the prevalence of exposure of Italian children to a broad array of potential carcinogenic factors. 


\section{Additional file}

Additional file 1: Table S1. Number of participating subjects by region and weight of each region. Table S2. Participation of mother and father at the interview, for a selection of the questionnaire sections. Table S3. SETIL study. Distribution by participation to ELF magnetic fields $48 \mathrm{~h}$ measurements. Table S4. Occupational condition of controls' parents from one year before conception until child's diagnosis. Table S5. - Parental employment status of controls, by region.

\section{Abbreviations}

ALL: Acute lymphoblastic leukaemia; AnLL: Acute lymphoblastic leukaemia; Cl: Confidence interval; ELF-MF: Extremely low fields magnetic fields; LHA: Local health authority; NHL: Non Hodgkin lymphoma; RR: Relative risk.

\section{Competing interests}

The authors declare they have no competing interests.

\section{Authors' contributions}

CM Coordinated the SETIL study and the writing group for this paper. SM $L M$ and RR drafted the paper, $A R, A B$, prepared the data analyses, AS coordinated the statistical analyses for the ELF-MF and other risk factors, $L B$ GM, CR, PZ, AG, SC, LG, LLL, PM, UK, LC, PB, CG, EC, EG, GA, GN, DFM, VB, FP†, PM, LM, MC, MC, VC, MVT, RMV, FF, RH, SL, SR, AP contributed with the study coordination, data collection, the discussion of results and the critical revision of the paper. SM, LM, RR, AS, LB, GM, PZ, SC, LG, PM, UK, LC, CG, EC, GA, DFM, FPt, LM, MC, MVT, FF, RH, SL, SR, AP contributed to the study design. $\mathrm{FF}, \mathrm{RH}, \mathrm{SL}, \mathrm{SR}, \mathrm{AP}$ also contributed to the planning, coordination and statistical analyses of specific sections of the SETIL study. All authors read and approved the final manuscript.

\section{Acknowledgements}

Our heartfelt thanks to the children who participated in the SETIL study and their families.

The SETIL study was financially supported by research grants received by AIRC (Italian Association on Research on Cancer), MIUR (Ministry for Instruction, University and Research, PRIN Program), Ministry of Health (Ricerca Sanitaria Finalizzata Program), Ministry of Labour and Welfare, Associazione Neuroblastoma, Piemonte Region (Ricerca Sanitaria Finalizzata Regione Piemonte Program), Liguria Region, Comitato per la vita "Daniele Chianelli"-Associazione per la Ricerca e la Cura delle Leucemie, Linfomi e Tumori di Adulti e Bambini, (Perugia).

A special thank to Ms. Victoria Franzinetti for her careful revision of the manuscript.

\section{Collaborators}

The SETIL study started thanks to the scientific contribution of Prof. Benedetto Terracini and of the late Prof. Guido Paolucci. The SETIL study in the various participating regions was coordinated by: Giorgio Assennato (ARPA_Puglia, Bari) and Gigliola de Nichilo (ASL BT, Dipartimento di Prevenzione, SPESAL, Barletta); Luigi Bisanti, and Giuseppe Sampietro (Servizio di Epidemiologia, ASL di Milano, Milano); Santina Cannizzaro (Lega Italiana per la Lotta contro i Tumori Onlus Sez. Provinciale di Ragusa, Ragusa Ibla); Egidio Celentano (ArSan, Agenzia regionale sanitaria della Campania, Napoli); Pierluigi Cocco (Dipartimento di sanità pubblica, Sezione di medicina del lavoro, Università di Cagliari, Cagliari); Marina Cuttini (Unità di Epidemiologia, Ospedale Pediatrico Bambino Gesù, Roma) and Veronica Casotto (IRCCS Burlo Garofolo, Trieste); Corrado Magnani (Study PI; CPO Piemonte and University of Eastern Piedmont, Novara); Stefano Mattioli (Unità Operativa di Medicina del Lavoro, Università di Bologna, Bologna); Domenico Franco Merlo and Vittorio Bocchini (Epidemiologia, Biostatistica e Trials Clinici, IRCCS AOU San Martino-IST, Genova); Paola Michelozzi and Ursula Kirchmayer (Dipartimento di Epidemiologia del Servizio Sanitario Regionale, Roma); Lucia Miligi (Unità di epidemiologia ambientale e occupazionale, ISPO Istituto per lo Studio e la Prevenzione Oncologica, Firenze); Liliana Minelli (Dipartimento di Specialità Medico Chirurgiche e Sanità Pubblica- Sezione di Sanità Pubblica Università degli Studi di Perugia, Perugia); Franco Pannelli and Paola Mosciatti (Università di Camerino, Dipartimento di Medicina Sperimentale e di Sanità Pubblica, Camerino); Maria Valeria Torregrossa (Dipartimento di Scienze per la Promozione della
Salute Sezione Igiene, Università degli Studi di Palermo, Palermo); Paola Zambon (Università di Padova, Padova); Riccardo Haupt (Istituto Giannina Gaslini, Genova); Francesco Forastiere (Dipartimento di Epidemiologia del Servizio Sanitario Regionale, Roma).

The ELF-MF component of the SETIL study was designed and carried out with the contribution of: Daniele Andreuccetti (IROE-CNR, Firenze); Giovanni d'Amore, Laura Anglesio, Stefano Roletti and Mauro Magnoni (ARPA-Piemonte, Ivrea); Myris Erna (PMP Fisica, Padova); Marco Gilardetti and Ombretta Pons (CPO Piemonte, Torino); Mirti Lombardi (PMP, Ancona); Alessandra Benvenuti and Patrizia Legittimo (Unità di epidemiologia ambientale e occupazionale, ISPO Istituto per lo Studio e la Prevenzione Oncologica, Firenze); Piero Mozzo (Centro Radioattività Ambientale, Verona); Andrea Poggi and Silvia Bucci (ARPAT, Firenze); Alessandro Polichetti and Paolo Vecchia (Dipartimento Tecnologia e Salute, Istituto Superiore di Sanità, Roma); Giuseppe Sgorbati (PMP, Milano); Bianca Stievano, Maria Rosa and Renzo Biancotto (ARPA Veneto, Padova); Santi Tofani (Servizio di Fisica Sanitaria, ASL Ivrea); Massimo Valle (PMP Fisica, Genova).

We also acknwoledge the contribution of many pediatric oncology departments and a special thank goes to: Maurizio Aricò, Gabriella Bernini, Alma Lippi (Dipartimento di Oncoematologia, AOU Meyer, Firenze); Pierfranco Biddau (Servizio di Oncologia Pediatrica, Ospedale Microcitemico Cagliari); Franco Locatelli (Università di Pavia, Pavia \& Ospedale Bambino Gesù, Roma); Lia Lidia Luzzatto (ASL 1, Torino); Giuseppe Masera (Clinica Pediatrica, Università Milano-Bicocca, Monza); Margherita Nardi (Dipartimento di Oncoematologia, AOU di Pisa, Pisa); Andrea Pession (Paediatric OncologyHaematology, University of Bologna, Bologna); Vincenzo Poggi (Dipartimento di Oncologia, A.O.R.N. Santobono-Pausilipon, Napoli); Alessandro Pulsoni (Cattedra di Ematologia, Università La Sapienza, Roma); Carmelo Rizzari (A.O. San Gerardo, Fondazione MBBM, Monza); Giovanna Russo (Divisione di Ematologia ed Oncologia pediatrica Università di Catania, Catania); Gino Schilirò (Divisione di Ematologia ed Oncologia pediatrica, Università di Catania, Catania); Roberto Targhetta (Servizio di Oncoematologia Pediatrica, Ospedale Microcitemico Cagliari); Stefania Varotto (Oncoematologia pediatrica, Dipartimento di Pediatria, Università di Padova).

Finally, the following persons also contributed to the SETIL study: Alessandra Benvenuti and Patrizia Legittimo (Unità di epidemiologia ambientale e occupazionale, ISPO Istituto per lo Studio e la Prevenzione Oncologica, Firenze); Francesco Bochicchio, Cristina Nuccitelli and Serena Risica (Istituto Speriore di Sanità); Roberto Calisti (SPreSAL, ASUR Marche, Civitanova, Macerata); Manuela Chiavarini (Dipartimento di Specialità Medico Chirurgiche e Sanità Pubblica- Sezione di Sanità Pubblica Università degli Studi di Perugia, Perugia; Gian Luca De Salvo (Sperimentazioni Cliniche e Biostatistica - Istituto Oncologico Veneto IOV-IRCCS, Padova); Elena Duglio (IRCCS, AOU San Martino-IST, Genova); Daniela Ferrante (CPO Piemonte, Novara); Andrea Farioli (Unità Operativa di Medicina del Lavoro, Università di Bologna, Bologna); Lorenzo Gafà (Lega Italiana per la Lotta contro i Tumori Onlus Sez. Provinciale di Ragusa, Ragusa Ibla); Claudia Galassi (Unità dei Epidemiologia dei Tumori, AO Città della Salute e della Scienza, Torino); Luigi Gelli (Struttura Regionale dell'Autorità Ambientale, Regione Campania, Napoli); Alessandra Greco (Istituto Oncologico Veneto - IRCCS Padova, Padova); Erni Guarino (Istituto Nazionale Tumori, Napoli); Paolo Guidotti (ITI, Firenze); Pia Massaglia (AO Ospedale Infantile Regina Margherita, Neuropsichiatria Infantile, Torino); Daniele Monetti (Istituto Oncologico Veneto IRCCS, Padova); Salvatore Panico (Università di Napoli, Napoli); Assunta Rasulo, and Ornella Ru (CPO Piemonte, Torino); Giuseppe Miceli (Azienda Sanitaria Locale 7, Ragusa); Donato Sivo (Università di Bari, Bari); Letizia Sommani (ASF Firenze, Firenze); Rosaria Maria Valenti (Dipartimento di Scienze per la Promozione della Salute Sezione Igiene, Università degli Studi di Palermo, Palermo); Rosario Tumino (Registro Tumori di Ragusa, Ragusa).

\section{Author details}

${ }^{1}$ Medical Statistics \& Cancer Epidemiology Unit - Department of Translational Medicine, CPO Piemonte and University of Eastern Piedmont, V. Solaroli 17, Novara 28100, Italy. ${ }^{2}$ Section of Occupational Medicine, Department of Internal Medicine, Geriatrics and Nephrology, University of Bologna, Bologna, Italy. ${ }^{3}$ Occupational and Environmental Epidemiology Unit, ISPO Cancer Prevention and Research Institute, Florence, Italy. ${ }^{4}$ Cancer Epidemiology Unit, CPO Piemonte Novara, Novara, Italy. ${ }^{5}$ Paediatric Oncology-Haematology "Lalla Seràgnoli", Policlinico S.Orsola-Malpighi, Bologna, Italy. 'Retired, formerly: IASI-CNR, Roma, Italy. ${ }^{7}$ Clinica Pediatrica, Università Milano Bicocca, Monza, Italy. ${ }^{8}$ A.O. San Gerardo, Fondazione MBBM, Monza, Italy. 
${ }^{9}$ Epidemiologia, ASL di Milano, Milano, Italy. ${ }^{10}$ Registro Tumori del Veneto, Università di Padova, Padova, Italy. ${ }^{11}$ Lega Italiana per la Lotta contro i Tumori Onlus Sez, Provinciale di Ragusa, Ragusa Ibla, Italy. ${ }^{12}$ ASL 1 - Torino, Torino, Italy. ${ }^{13}$ Occupational and Environmental Epidemiology Unit, ISPO Cancer Prevention and Research Institute Firenze, Firenze, Italy. ${ }^{14} \mathrm{UOC}$ Epidemiologia Ambientale, Dipartimento Epidemiologia Regione Lazio, Roma, Italy. ${ }^{15}$ Dipartimento Epidemiologia Regione Lazio, Roma, Italy. ${ }^{16}$ Dipartimento di Sanità Pubblica, Sezione di Medicina del Lavoro, Università di Cagliari, Cagliari, Italy. ${ }^{17}$ Servizio di Oncoematologia Pediatrica, Ospedale Microcitemico Cagliari, Cagliari, Italy. ${ }^{18}$ AOU S.Giovanni Battista e CPO Piemonte, Torino, Italy. ${ }^{19} \mathrm{~S}$. O. Analisi e Monitoraggio, ARSAN - Agenzia Regionale Sanitaria della Campania, Napoli, Italy. ${ }^{20}$ Istituto Nazionale Tumori, Napoli, Italy. ${ }^{21}$ ARPA - Puglia, Bari, Italy. ${ }^{22}$ ASL BT. Dipartimento di Prevenzione, SPESAL, Barletta, Italy. ${ }^{23}$ Epidemiology, Biostatistics and Clinical Trials, IRCCS Azienda Ospedaliera Universitaria San Martino- IST Istituto Nazionale per la Ricerca sul Cancro, Genova, Italy. ${ }^{24}$ Epidemiology, Biostatistics and Clinical Trials, IRCCS AOU San Martino- IST Istituto Nazionale per la Ricerca sul Cancro, Genova, Italy. ${ }^{25}$ Registro Tumori di Macerata e Università di Camerino, Camerino, Italy. ${ }^{26}$ Università di Camerino, Dipartimento di Medicina Sperimentale e di Sanità Pubblica, Camerino, Italy. ${ }^{27}$ Dipartimento di Medicina Sperimentale - Sezione di Sanità Pubblica Università degli Studi di Perugia, Perugia, Italy. ${ }^{28}$ Dipartimento di Medicina Sperimentale - Sezione di Sanità Pubblica, Università degli Studi di Perugia, Perugia, Italy. ${ }^{29}$ Unità di Unità di Ricerca di Epidemiologia Perinatale, Ospedale Pediatrico Bambino Gesù, Roma, Italy. ${ }^{30}$ IRCCS Burlo Garofolo, Trieste, Italy. ${ }^{31}$ Dipartimento di Scienze per la Promozione della Salute Sez. Igiene, Università degli Studi di Palermo, Palermo, Italy. ${ }^{32}$ Dipartimento di Scienze per la Promozione della Salute Sez.lgiene, Università degli Studi di Palermo, Palermo, Italy. ${ }^{33} \mathrm{UOC}$ Epidemiologia Ambientale, Dipartimento Epidemiologia Regione Lazio, Roma, Italy. ${ }^{34}$ Istituto Giannina Gaslini, Genova, Italy. ${ }^{35}$ National Centre for Epidemiology, Surveillance and Health Promotion, National Institute of Health, Rome, Italy. ${ }^{36}$ Retired, formerly: Department of Technology and Health, National Institute of Health, Rome, Italy.

Received: 3 July 2014 Accepted: 4 December 2014 Published online: 24 December 2014

\section{References}

1. Eden T: Aetiology of childhood leukaemia. Cancer Treat Rev 2010 36:286-297

2. Parodi S, Haupt R: The epidemiology of neuroblastoma. New York: Nova science Publ; 2009.

3. McNally RJ, Parker L: Environmental factors and childhood acute leukemias and lymphomas. Leuk Lymphoma 2006, 47:583-598.

4. Belson M, Kingsley B, Holmes A: Risk factors for acute leukemia in children: a review. Environ Health Perspect 2007, 115:138-145.

5. Pisani P, Parodi S, Magnani C: Le cause ed i fattori di rischio delle neoplasie pediatriche. Epidemiol Prev 2013, 37(Suppl 1):234-250.

6. Urayama KY, Buffler PA, Gallagher ER, Ayoob JM, Ma X: A meta-analysis of the association between day-care attendance and childhood acute lymphoblastic leukaemia. Int J Epidemiol 2010, 39:718-732

7. Lagorio S, Ferrante D, Ranucci A, Negri S, Sacco P, Rondelli R, Cannizzaro S, Torregrossa MV, Cocco P, Forastiere F, Miligi L, Bisanti L, Magnani C. Exposure to benzene and childhood leukaemia: a pilot case-control study. BMJ Open. 2013; 3(2). doi:10.1136/bmjopen-2012-002275.

8. Bochicchio F, Campos Venuti G, Monteventi F, Nuccetelli C, Piermattei S, Risica $S$, Tommasino L, Torri G. Indoor exposure to gamma radiation in Italy. In: Proceedings of International Congress on Radiation Protection. IRPA9: April 14-19, 1996, Vienna. Vol.2: 190-192.

9. Pession A, Rondelli R: Collection and transfer of data: the AIEOP model. Bone Marrow Transplant 2008, 41(Suppl 2):S35-S38.

10. Ferrari A, Dama E, Pession A, Rondelli R, Pascucci C, Locatelli F, Ferrari S, Mascarin M, Merletti F, Masera G, Aricò M, Pastore G: Adolescents with cancer in Italy: entry into the national cooperative paediatric oncology group AIEOP trials. Eur J Cancer 2009, 45:328-334.

11. Salvan A, Pons O, Roletti S, Erna M, Liguori F, Ciccolallo L, Galassi C, Miligi L, Poggi A, Cannizzaro S, Tumino R, Bortot P, Polichetti A, Vecchia P, Magnani $C$ for the SETIL workgroup. A pilot study of residential exposure to extremely low frequency magnetic fields for the Italian epidemiologic study of risk factors for childhood cancer (SETIL). In Kostarakis P and Stavroulakis P (eds). Proceedings of the Millennium Workshop on Biological
Effects of Electromagnetic Fields, Heraklion, Greece, 17-20 October 2000, pp 424-431.

12. AIRTUM Working group: I tumori in Italia - rapporto 2012. I tumori dei bambini e degli adolescenti. Epidemiol Prev 2013, 37(suppl 1):32-89.

13. Linet MS, Hatch EE, Kleinerman RA, Robison LL, Kaune WT, Friedman DR, Severson DK, Haines CM, Hartsock CT, Niwa S, Wacholder S, Tarone R: Residential exposure to magnetic fields and acute lymphoblastic leukemia in children. N Engl J Med 1997, 337:1-8.

14. UKCCS - UK Childhood Cancer Study Investigators: Exposure to powerfrequency magnetic fields and the risk of childhood cancer. Lancet 1999, 354:1925-1931.

15. Schüz J, Grigat J-P, Brinkmann K, Michaelis J: Residential magnetic fields as a risk factor for childhood acute leukaemia: results from a German population-based case-control study. Int J Cancer 2001, 91:728-735.

16. Ma X, Buffler PA, Layefsky M, Does MB, Reynolds P: Control selection strategies in case-control studies of childhood diseases. Am J Epidemiol 2004, 159:915-921.

17. ISTAT 2001 census ( $14^{\circ}$ Censimento della popolazione e delle abitazioni, 2001), data base on line [http://dawinci.istat.it/jsp/MD/dawinciMD.jsp, tavole Indice di possesso del Diploma scuola media superiore (19-34 anni) per sesso - Italia]. accessed on April 10th, 2014.

18. ISTAT Datawarehouse. http://dati.istat.it [selected tables: Istruzione e formazione/Popolazione 15 anni ed oltre per titolo di studio (selections: Italia, popolazione residente, classi di età quinquennali da 20 a 39 anni, anni 2004-2005)], accessed on April 10th, 2014

19. Greenland S, Sheppard AR, Kaune WT, Poole C, Kelsh MA, Childhood Leukemia-EMF Study Group: A pooled analysis of magnetic fields, wire codes, and childhood leukemia. Epidemiology 2000, 11:624-634.

20. Ahlbom A, Day N, Feychting M, Roman E, Skinner J, Dockerty J, Linet M, McBride M, Michaelis J, Olsen JH, Tynes T, Verkasalo PK: A pooled analysis of magnetic fields and childhood leukaemia. Br J Cancer 2000, 83:692-698

21. Kheifets L, Ahlbom A, Crespi CM, Draper G, Hagihara J, Lowenthal RM, Mezei G, Oksuzyan S, Schüz J, Swanson J, Tittarelli A, Vinceti M, Wunsch Filho $\mathrm{V}$ : Pooled analysis of recent studies on magnetic fields and childhood leukaemia. Br J Cancer 2010, 103:1128-1135.

22. Sardu C, Mereu A, Pitzalis G, Minerba L, Contu P: Smoking trends in Italy from 1950 to 2000. J Epidemiol Community Health 2006, 60:799-803.

23. Federico B, Kunst AE, Vannoni F, Damiani G, Costa G: Trends in educational inequalities in smoking in northern, mid and southern Italy, 1980-2000. Prev Med 2004, 39:919-926.

24. Colombo P, Scarpino V, Zuccaro P, Apolone G, Gallus S, La Vecchia C: Smoking in Italian women and men, 2001. Tumori 2002, 88:10-12.

25. Kaprio J, Sarna S, Fogelholm M, Koskenvuo M: Total and occupationally active life expectancies in relation to social class and marital status in men classified as healthy at 20 in Finland. J Epid Comm Health 1996, 50:653-660

26. Martikainen P: Women's employment, marriage, motherhood and mortality: a test of the multiple role and role accumulation hypotheses. Soc Sci Med 1995, 40:199-212.

27. Rudant J, Menegaux F, Leverger G, Baruchel A, Lambilliotte A, Bertrand Y Patte C, Pacquement H, Vérité C, Robert A, Michel G, Margueritte G, Gandemer V, Hémon D, Clavel J: Childhood hematopoietic malignancies and parental use of tobacco and alcohol: the ESCALE study (SFCE). Cancer Causes Control 2008, 19:1277-1290.

28. MacArthur AC, McBride ML, Spinelli JJ, Tamaro S, Gallagher RP, Theriault G: Risk of childhood leukemia associated with parental smoking and alcohol consumption prior to conception and during pregnancy: the cross-Canada childhood leukemia study. Cancer Causes Control 2008, 19:283-295

29. Lee KM, Ward MH, Han S, Ahn HS, Kang HJ, Choi HS, Shin HY, Koo HH, Seo $\mathrm{JJ}$, Choi JE, Ahn YO, Kang D: Paternal smoking, genetic polymorphisms in CYP1A1 and childhood leukemia risk. Leuk Res 2009, 33:250-258.

30. Milne E, Greenop KR, Scott RJ, Bailey HD, Attia J, Dalla-Pozza L, De Klerk NH, Armstrong BK: Parental prenatal smoking and risk of childhood acute lymphoblastic leukemia. Am J Epidemiol 2012, 175:43-53.

31. Farioli A, Legittimo P, Mattioli S, Miligi L, Benvenuti A, Ranucci A, Salvan A, Rondelli $R$, Conter $V$, Magnani C: Tobacco smoke and risk of childhood acute lymphoblastic leukemia: findings from the SETIL case-control study. Cancer Causes and Control 2014, 25:683-692.

32. Mattioli S, Farioli A, Legittimo P, Miligi L, Benvenuti A, Ranucci A, Salvan A Rondelli R, Magnani C, SETIL Study Group: Tobacco smoke and risk of 
childhood acute non-lymphocytic leukemia: findings from the SETIL Study. PLoS One 2014, 9:e111028. doi:10.1371/journal.pone.0111028.

33. Miligi L, Benvenuti A, Mattioli S, Salvan A, Tozzi GA, Ranucci A, Legittimo P, Rondelli R, Bisanti L, Zambon P, Canizzaro S, Kirchmayer U, Cocco P, Celentano E, Assennato G, Merlo DF, Mosciatti P, Minelli L, Cuttini M Torregrossa MV, Lagorio S, Haupt R, Risica S, Polichetti A, SETIL Working Group*, Magnani C: Risk of childhood leukaemia and non Hodgkin lymphoma after parental occupational exposure to solvents and other industrial exposures: the SETIL Study. Occup Environ Med 2013, 70:648-655.

34. Siemiatycki J, Day NE, Fabry J, Cooper JA: Discovering carcinogens in the occupational environment: a novel epidemiologic approach. J Natl Cancer Inst 1981, 66:217-225.

35. Buckley JD, Robison LL, Swotinsky R, Garabrant DH, LeBeau M, Manchester P, Nesbit ME, Odom L, Peters JM, Woods WG, Hammond D: Occupational exposures of parents of children with acute nonlymphocytic leukemia: a report from the Childrens Cancer Study Group. Cancer Res 1989, 49:4030-4037.

36. Schüz J, Kaletsch U, Meinert R, Kaatsch P, Michaelis J: Risk of childhood leukemia and parental self-reported occupational exposure to chemicals, dusts, and fumes: results from pooled analyses of German population-based case-control studies. Cancer Epidemiol Biomarkers Prev 2000, 9:835-838.

37. Reid A, Glass DC, Bailey HD, Milne E, Armstrong BK, Alvaro F, Fritschi L: Parental occupational exposure to exhausts, solvents, glues and paints, and risk of childhood leukemia. Cancer Causes Control 2011, 22:1575-1585.

\section{Submit your next manuscript to BioMed Central and take full advantage of:}

- Convenient online submission

- Thorough peer review

- No space constraints or color figure charges

- Immediate publication on acceptance

- Inclusion in PubMed, CAS, Scopus and Google Scholar

- Research which is freely available for redistribution 